\title{
Prevalence of the metabolic syndrome and cardiovascular disease risk in chemotherapy-treated testicular germ cell tumour survivors
}

\author{
P M Willemse ${ }^{1}$, J Burggraaf ${ }^{2}$, N A T Hamdy ${ }^{3}$, N I Weijl ${ }^{1}$, C Y Vossen ${ }^{4}$, L van Wulften ${ }^{1}$, \\ A Q M J van Steijn-van Tol ${ }^{1}$, F R Rosendaal ${ }^{5}$ and S Osanto*,1 \\ ${ }^{1}$ Department of Clinical Oncology, Leiden University Medical Center, Albinusdreef 2, 2333 ZA Leiden, The Netherlands; \\ ${ }^{2}$ Centre for Human Drug Research, Zernikedreef 8, 2333 CL Leiden, The Netherlands; ${ }^{3}$ Department of Endocrinology and \\ Metabolic Diseases, Leiden University Medical Center, Leiden, The Netherlands; ${ }^{4}$ Department of Thrombosis and Haemostasis, \\ Leiden University Medical Center, Leiden, The Netherlands and ${ }^{5}$ Department of Clinical Epidemiology, Leiden University Medical \\ Center, Leiden, The Netherlands
}

Background: Testicular cancer patients have an increased risk for cardiovascular disease (CVD), which might be related to the increased prevalence of the metabolic syndrome (MetS) in this group of patients.

Methods: We assessed the prevalence of MetS and calculated the 10-year CVD risk in a cohort of 255 testicular germ cell tumour survivors (median age, 38.7 years; interquartile range, 31-48) at a mean of 7.8 years after anti-cancer treatment, and compared these with data obtained from 360 healthy men.

Results: Survivors had an age-adjusted increased risk for MetS of 1.9 compared with that of healthy controls. The risk for MetS was highest in survivors treated with combination chemotherapy (CT) 2.3 (Adult Treatment Panel of the National Cholesterol Education Program classification) and 2.2 (International Diabetes Federation classification). The risk of MetS was especially increased in survivors with testosterone levels in the lowest quartile (OR, 2.5). Ten-year cardiovascular risk as assessed by the Framingham Risk Score (3.0\%) and Systemic Coronary Risk Evaluation (1.7\%) algorithms was low, independent of treatment, and was comparable to controls.

Conclusion: Testicular germ cell tumour survivors have an increased prevalence of MetS, with hypogonadism and CT treatment being clear risk factors for the development of the syndrome. The increased prevalence of MetS was not associated with an increased 10-year cardiovascular risk.

Testicular cancer, the most common cancer in male patients between 25 and 35 years of age, holds an excellent prognosis since the introduction of cisplatin-based chemotherapy (CT) in the treatment regimen (Einhorn, 1997). However, testicular cancer patients treated with CT or radiotherapy are reported to have a 25 - year risk of long-term cardiovascular complications of $\sim 16 \%$ (van den Belt-Dusebout et al, 2006). An increased incidence of cardiovascular events was indeed recently reported in germ cell tumour (GCT) survivors (Haugnes et al, 2010). Patients who had received $\mathrm{CT}$ were found to be more at risk than those patients

*Correspondence: Professor S Osanto; E-mail: s.osanto@lumc.nl

Received 2 January 2013; revised 14 April 2013; accepted 17 April 2013; published online 9 May 2013

(C) 2013 Cancer Research UK. All rights reserved 0007-0920/13 
treated with orchidectomy only (Huddart et al, 2003). Over the last two decades, concerns have been raised about the increased risk of cardiovascular morbidity and the increased prevalence of the metabolic syndrome (MetS) with the use of certain treatment modalities in specific cancer types (de Forni and Armand, 1994; Yeh et al, 2004; Carver et al, 2007). Studies in GCT survivors report a wide variation in the prevalence of MetS ranging from $13 \%$ to 39\% (Nuver et al, 2005; Haugnes et al, 2007; Wethal et al, 2007) compared with a prevalence of $15 \%$ in non-diabetic adult Europeans (Hu et al, 2004).

MetS is a cluster of metabolic and interrelated cardiovascular risk factors, which directly promotes atherosclerotic cardiovascular disease (CVD) (Ingelsson et al, 2006). Various expert panels have developed classifications of MetS to facilitate screening for cardiovascular risk factors, including the Adult Treatment Panel of the National Cholesterol Education Program (NCEP-ATP III), which modified the definition based on similar characteristics used by the WHO (Table 1; Balkau and Charles, 1999; World Health Organization, 1999) and the MetS score developed by the International Diabetes Federation (IDF) (Alberti et al, 2006). A meta-analysis of 21 prospective American and European cohort studies using the NCEP-ATPIII or WHO criteria indicated that patients with high MetS prevalence have an increased incidence and mortality for CVD (Galassi et al, 2006). Another metaanalysis, including 37 studies and 172573 individuals (Gami et al, 2007), showed that MetS carried a relative risk (RR) of cardiovascular events and deaths of 1.78 (95\% CI, 1.58-2.0).

In all classifications used for the MetS, main risk factors for CVD, such as smoking, age, and prothrombotic and proinflammatory state, are excluded to simplify outpatient screening. Of particular interest for GCT patients is that androgen deficiency has been found to be a risk factor for the development of the MetS, and cured survivors are often found to have some degree of CTinduced hypogonadism, which may persist for up to 10 years after treatment (Nord et al, 2003). Hypogonadism can itself promote obesity and insulin resistance, and in turn visceral obesity promotes hypogonadism. Another possible explanation for the observed increased CVD risk in GCT survivors is the fact that patients' testicular germ cell cancer may be aetiologically linked to other male reproductive abnormalities as a part of the so-called 'testicular dysgenesis syndrome' (TDS) (Skakkebaek et al, 2007). This syndrome is present in a proportion of GCT patients before the diagnosis of the malignancy and in the survivors, and it is biologically plausible that the syndrome may predispose to development of MetS in later years (Ivell and Nand-Ivell, 2009).

Increasing numbers of patients in Europe and the United States have risk factors for CVD. This has led physicians to stratify patients according to risk algorithms of which the Framingham Risk Score (FRS) (Wilson et al, 1987) and the Systemic Coronary Risk Evaluation (SCORE) are most commonly used (Conroy et al, 2003). In contrast to the fasting blood samples used in the assessment of the MetS, the FRS can be calculated using non-fasting blood samples for cholesterol and HDL-cholesterol, and the major CVD risk factors, such as smoking and age, are also included in the FRS. The SCORE project, which collected and analysed data from 12 European cohort studies, was developed to estimate cardiovascular risk in European clinical practice.

The large differences in MetS and CVD prevalence reported in the literature in GCT patients has prompted us to use both the risk CVD prediction models to calculate 10-year cardiovascular risk in our cohort of long-term GCT survivors compared with healthy male subjects. We assessed MetS prevalence using both NCEPATPIII and IDF classifications to compare differences in outcome and to facilitate comparison with other studies.

\section{PATIENTS AND METHODS}

Patients. In a cross-sectional study design, all patients with a primary GCT originating in the testis, who attended the outpatient clinic of the Clinical Oncology Department of the Leiden University Medical Center between 2008 and 2010 for routine follow-up, were invited to take part in the study and 255 eligible patients were included (Figure 1). Seventy-nine patients had stage-I disease; 58 were treated with orchidectomy alone ('surgery patients') and 21 seminoma patients also received one adjuvant dose of carboplatin (AUC7; 'carboplatin patients'). Patients $(n=176)$ with disseminated disease were treated with orchidectomy and combination CT, primarily bleomycin, etoposide, and cisplatin ('combination-CT patients').

Data of 360 healthy men from the general population, living in the same geographical area, obtained from the general practitioners' health screening records were used as control. These data were obtained in 2009 as part of a programme in which apparently healthy subjects were screened for cardiovascular risk factors.

Methods. For all patients and controls, medical history (including smoking behaviour) was taken; body weight, height, body mass index (BMI, $\mathrm{kg} \mathrm{m}^{-2}$ ), and waist circumference (WHO standards) were recorded, and blood pressure was measured in duplicate with the participants in a semi-recumbent position after at least 5 min rest. Blood samples were obtained after an overnight fast and measured for cholesterol, HDL-cholesterol, LDL-cholesterol, and triglycerides using routine assays. The patients' blood was also analysed for C-reactive protein (CRP) concentrations (standard assay), HbAlc and insulin (LEIA), and gonadal status. The latter was evaluated by measuring serum concentrations of luteinising hormone (LH), follicle-stimulating hormone (FSH) by using electrochemoluminescene immunoassays, total testosterone (TT) and estradiol (E2) by using standard radioimmunoassays, and sex hormone-binding globulin (SHBG) by using a luminescence enzyme immunoassay. Hypogonadism was defined as a

Table 1. Metabolic syndrome criteria according to two different classification systems

\begin{tabular}{|c|c|c|}
\hline & NCEP-ATPIII & IDF \\
\hline Hypertension & $\mathrm{BP}_{\text {systolic }} \geqslant 135 \mathrm{~mm} \mathrm{Hg}$ and $B P_{\text {diastolic }} \geqslant 85 \mathrm{~mm} \mathrm{Hg}$ & $\mathrm{BP}_{\text {systolic }} \geqslant 135 \mathrm{~mm} \mathrm{Hg}$ or $\mathrm{BP}_{\text {diastolic }} \geqslant 85 \mathrm{~mm} \mathrm{Hg}$ \\
\hline Obesity & Waist circumference $\geqslant 102 \mathrm{~cm}$ & Waist circumference $\geqslant 94 \mathrm{~cm}$ or $\mathrm{BMl}>30 \mathrm{~kg} \mathrm{~m}^{-2}$ \\
\hline Insulin resistance & fasting glucose $\geqslant 6.1 \mathrm{mmoll}^{-1}\left(110 \mathrm{mg} \mathrm{dl}^{-1}\right)$ & Fasting glucose $\geqslant 5.6 \mathrm{mmoll}^{-1}\left(100 \mathrm{mg} \mathrm{dl}^{-1}\right)$ \\
\hline Dyslipidemia & $\mathrm{HDL}$-cholesterol $<1.03 \mathrm{mmoll}^{-1}\left(40 \mathrm{mg} \mathrm{dl}^{-1}\right)$ or statin usage & $\mathrm{HDL}$-cholesterol $<1.03 \mathrm{mmoll}^{-1}\left(40 \mathrm{mg} \mathrm{dl}^{-1}\right)$ or statin usage \\
\hline Hypertriglyceridemia & Triglyceride $\geqslant 1.7 \mathrm{mmoll}^{-1}\left(150 \mathrm{mg} \mathrm{dl}^{-1}\right)$ & Triglyceride $\geqslant 1.7 \mathrm{mmoll}^{-1}\left(150 \mathrm{mg} \mathrm{dl}^{-1}\right)$ \\
\hline Metabolic syndrome & $\geqslant 3$ Criteria & Obesity and $\geqslant 2$ other criteria \\
\hline
\end{tabular}




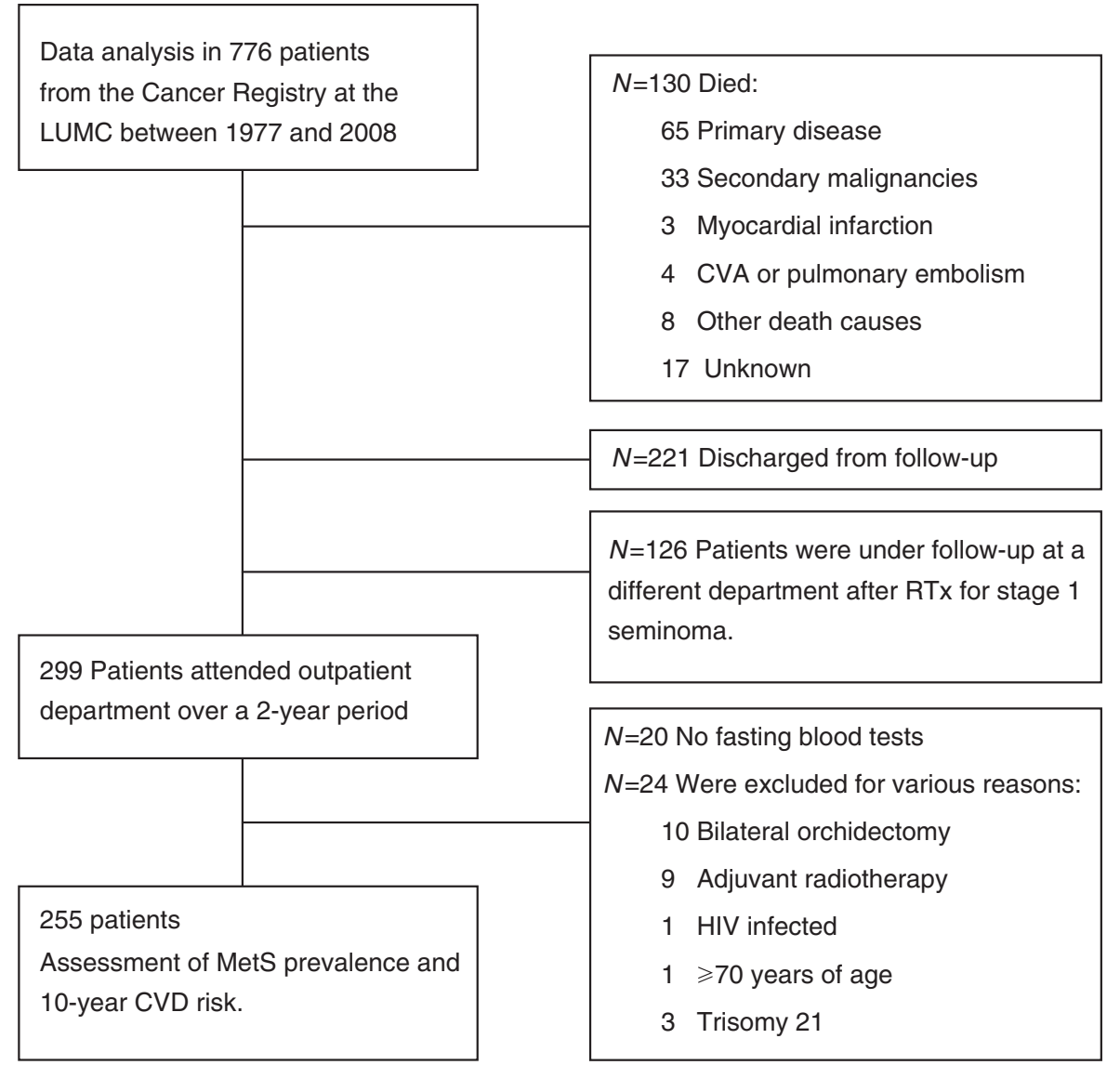

Figure 1. Flowchart inclusion of GCT patients. Major events (dates of diagnosis and mortality of CVD, defined as coronary heart disease, but not as stroke or peripheral artery disease, and date of most recent medical information, vital status during follow-up, and discharge), including annual verification of mortality and cause of death from hospital medical records, general practitioner, and municipal and national cancer data records were retrieved from the cancer registry and medical.

fasting-morning serum TT concentration of $<10.4 \mathrm{nmoll}^{-1}$ (Lackner et al, 2007). Four patients with disseminated disease received testosterone replacement therapy and were excluded for hormonal analysis.

Metabolic syndrome and 10-year cardiovascular risk evaluation. We used the NCEP-ATPIII criteria (National Cholesterol Education Program (NCEP) Expert Panel on Detection, Evaluation, and Treatment of High Blood Cholesterol in Adults (Adult Treatment Panel III), 2002) and IDF risk score charts (Alberti et al, 2006; Table 1) to establish the prevalence of MetS. The 10-year cardiovascular risk profile was calculated using FRS (Wilson et al, 1987) and SCORE (Conroy et al, 2003).

Statistical analysis. SPSS 19 for Windows software package (SPSS Inc., Chicago, IL, USA) was used for statistical analysis. The $\chi^{2}$-test for categorical variables and Student's $t$-test or Mann-Whitney test (two-sided) for non-normally distributed variables were used as appropriate. Results are expressed as interquartile range (IQR), mean \pm s.d., or as median (range). Odds ratios for MetS were calculated using logistic regression analysis and with adjustment for age and kidney function as continuous variables, and smoking and hypogonadism as binary variables. The incidence of MetS was also analysed according to serum testosterone quartiles using $\chi^{2}$-test for categorical variables. A $P$-value of $<0.05$ (two-tailed) was considered statistically significant. We also investigated whether there was an association between the time elapsed between treatment and the occurrence of MetS by linear regression.
Finally, we used the raw data provided in three reports (Nuver et al, 2005; Haugnes et al, 2007; Wethal et al, 2007) in the literature on MetS in GCT patients to calculate the odds ratios.

\section{RESULTS}

Patient characteristics. The median (range) cumulative carboplatin dose administered to survivors was 1015 (7301700) mg (Table 2). Seven survivors who were eventually treated with combination CT were first treated with single-dose carboplatin for stage-1 seminoma, and one survivor was treated with three cycles of carboplatin before they developed distant metastasis. The median cumulative cisplatin dose administered to the survivors receiving combination CT was 604 (0-1750) mg; two patients received carboplatin instead of cisplatin as part of their combination CT.

The summary of the patient characteristics (Table 2) showed that at the time of the analysis there were no major differences in age between the different treatment groups of GCT survivors and the controls. Seminoma patients (42.4 years; IQR 35-50) were older than non-seminoma patients (38.0 years; IQR 29-45; $P=0.003)$. The BMI and waist circumference were comparable between the groups.

Smoking behaviour was comparable in all groups of patients and the controls, and amounted to $\sim 40 \%$. Moreover, there were no major differences in blood pressure and renal function, assessed as creatinine clearance using the Cockroft formula, between the groups. 


\begin{tabular}{|c|c|c|c|c|c|c|c|}
\hline \multicolumn{5}{|c|}{ Treatment groups } & \multirow[b]{2}{*}{$\begin{array}{l}\text { All survivors } \\
(\mathbf{N}=255)\end{array}$} & \multirow[b]{2}{*}{$P$-value ${ }^{a}$} & \multirow[b]{2}{*}{$P$-value ${ }^{b}$} \\
\hline Parameters & $\begin{array}{l}\text { Healthy subjects } \\
\qquad(\boldsymbol{N}=360)\end{array}$ & $\begin{array}{l}\text { Surgery } \\
(N=58)\end{array}$ & $\begin{array}{l}\text { Carboplatin } \\
\qquad(\mathbf{N}=21)\end{array}$ & $\begin{array}{l}\text { Combination CT } \\
(\mathbf{N}=176)\end{array}$ & & & \\
\hline \multicolumn{8}{|c|}{ Demographics: mean \pm s.d., median (min-max) } \\
\hline Age at diagnosis (years) & NA & $\begin{array}{c}30.4 \pm 8.3 \\
28.9(20.0-61.9)\end{array}$ & $\begin{array}{c}37.6 \pm 12.2 \\
33.8(24.8-50.6)\end{array}$ & $\begin{array}{c}31.2 \pm 8.8 \\
29.6(14.2-54.2)\end{array}$ & $\begin{array}{c}31.4 \pm 8.7 \\
29.8(14.2-61.9)\end{array}$ & $\sim$ & $\sim$ \\
\hline Age at blood analysis (years) & $\begin{array}{c}43.1 \pm 14.6 \\
44.0(18-70)\end{array}$ & $\begin{array}{c}36.6 \pm 10.4 \\
36.5(20.1-69.5)\end{array}$ & $\begin{array}{c}42.1 \pm 12.0 \\
39.3(26.8-57.4)\end{array}$ & $\begin{array}{c}38.7 \pm 10.9 \\
38.7(18.2-63.4)\end{array}$ & $\begin{array}{c}39.2 \pm 10.7 \\
38.3(18.2-69.5)\end{array}$ & NS & NS \\
\hline $\begin{array}{l}\text { Interval between curative treatment } \\
\text { and blood analysis (years) }\end{array}$ & NA & $\begin{array}{c}6.2 \pm 6.7 \\
3.2(0.1-2)\end{array}$ & $\begin{array}{c}4.5 \pm 3.5 \\
3.1(0.7-13.2)\end{array}$ & $\begin{array}{c}8.8 \pm 7.8 \\
6.3(0.6-30.2)\end{array}$ & $\begin{array}{c}7.8 \pm 7.4 \\
5.0(0.1-30.2)\end{array}$ & $\sim$ & $\sim$ \\
\hline \multicolumn{8}{|c|}{ Clinical characteristics: median (min-max) } \\
\hline Body weight $(\mathrm{kg})$ & $85(54-138)$ & $82(60-138)$ & $83(64-132)$ & $85(60-126)$ & $84(60-138)$ & 0.005 & 0.01 \\
\hline Height (m) & $1.80(1.57-2.06)$ & $1.85(1.65-1.99)$ & $1.83(1.69-1.98)$ & $1.83(1.65-2.01)$ & $1.83(1.65-2.01)$ & 0.006 & $<0.001$ \\
\hline Body mass index $\left(\mathrm{kg} \mathrm{m}^{-2}\right)$ & $25.8(19.5-42.6)$ & $24.2(16.8-38.5)$ & $25.0(20.5-35.8)$ & $25.6(18.4-36.4)$ & $25.5(16.8-38.5)$ & NS & 0.01 \\
\hline Waist circumference $(\mathrm{cm})$ & $94(74-130)$ & $92(85-134)$ & $96(81-137)$ & $96(67-124)$ & $96(67-137)$ & $<0.001$ & 0.003 \\
\hline Systolic blood pressure $(\mathrm{mm} \mathrm{Hg})^{c}$ & $130(110-200)$ & $122(95-185)$ & $130(90-155)$ & $126(90-200)$ & $125(90-200)$ & NS & 0.006 \\
\hline Diastolic blood pressure $(\mathrm{mm} \mathrm{Hg})^{c}$ & $80(62-110)$ & $80(54-110)$ & $80(65-90)$ & $80(53-114)$ & $80(53-114)$ & NS & NS \\
\hline $\begin{array}{l}\text { Creatinine clearance (Cockroft } \\
\text { formula; } \mathrm{ml} \mathrm{min}^{-1} \text { ) }\end{array}$ & & $122(84-205)$ & $120(70-165)$ & $123(56-217)$ & $122(56-217)$ & $\sim$ & $\sim$ \\
\hline \multicolumn{8}{|c|}{ 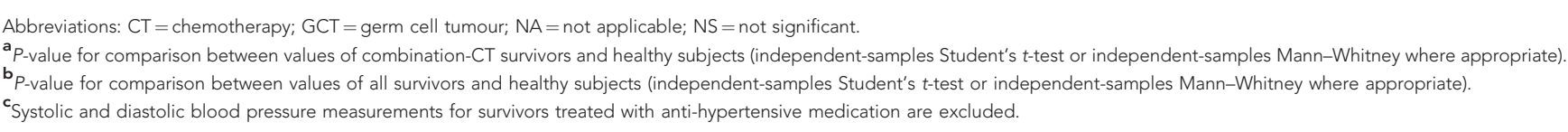 } \\
\hline
\end{tabular}

Combination-CT patients had significantly higher fasting serum concentrations of cholesterol, LDL-cholesterol, and triglyceride than that in controls, and higher serum cholesterol and triglyceride concentrations compared with that in surgery patients (Table 3). Carboplatin patients had higher fasting serum cholesterol $(P=0.04)$ and LDL-cholesterol $(P=0.004)$ concentrations than that in healthy subjects. Survivors treated with surgery only had higher LDL-cholesterol concentrations than that in healthy subjects $(P=0.04)$. Fasting serum HDL-cholesterol concentrations did not differ significantly between treatment groups. Fasting serum glucose concentrations did not differ between treatment groups and healthy subjects (Table 3), and only five patients developed diabetes in the follow-up period. The CRP concentrations were elevated in 10 survivors (3.8\%), but did not differ between the groups. Patients with disseminated disease treated with combination CT had significantly lower testosterone and higher FSH levels than that in stage-I patients who only underwent orchidectomy (Table 3). Thirty-four (12.9\%) GCT survivors had hypogonadism; three of whom (4.5\%) had orchidectomy alone and $31(17.6 \%)$ had combination CT in addition to orchidectomy (Table 3). There were no differences in gonadal hormone levels between patients treated with orchidectomy only or patients treated with adjuvant single-dose carboplatin.

Prevalence of MetS. Using the NCEP-ATPIII criteria, GCT survivors had a significantly higher prevalence of obesity, dyslipidemia, and hypertriglyceridemia compared with agematched healthy subjects (Table 4, upper part). In particular, survivors treated with combination CT had the highest prevalence of all NCEP-ATPIII criteria compared with healthy subjects. The prevalence of MetS did not differ between survivors treated with orchidectomy only or survivors treated with an orchidectomy and carboplatin. The prevalence of MetS in all groups was almost twofold higher when classified according to the IDF criteria compared with the NCEP-ATPIII criteria. There was only a minimal influence ( $\beta$-coefficient $=0.02$ cases per year) of the time elapsed between curative treatment and the prevalence of MetS.

GCT survivors had an increased age-adjusted NCEP-ATPIII risk of 1.9 (95\% CI, 1.1-3.2) and an IDF risk of 1.8 (95\% CI, 1.2-2.7; Table 4). Compared with healthy subjects, combinationCT survivors had the highest age-adjusted risk to develop MetS, that is, 2.3 (95\% CI, 1.3-4.0, NCEP-ATPIII classification) and 2.2 (95\% CI, 1.4-3.3, IDF classification; Table 4). In surgeryalone survivors, age-adjusted risk to develop MetS was, respectively, 1.5 (95\% CI, 0.6-3.9, NCEP-ATPIII) and 1.7 (95\% CI, 0.8-3.6, IDF) compared with healthy subjects. Irrespective of the use of the IDF or NCEP-ATPIII criteria, survivors with the lowest quartile testosterone levels $\left(<12.0 \mathrm{nmoll}^{-1}\right)$ had a MetS prevalence higher than the other three quartiles (OR, 2.5 and 95\% CI, 1.3-4.7; and OR, 1.7 and 95\% CI, 0.8-3.6, respectively). The prevalence of MetS was not associated with other gonadal hormone concentrations or with alcohol use (data not shown).

According to the NCEP-ATPIII criteria, GCT survivors who were smokers had a twofold increased risk (95\% CI, 1.0-4.0) for MetS compared with non-smokers. In healthy subjects, smokers had a 1.6-fold increased risk (95\% CI, 0.7-3.4) for MetS compared with non-smokers. Smoking-adjusted risk of MetS for all survivors and for combination-CT survivors alone compared with healthy subjects was, respectively, 1.8 (95\% CI, 1.1-3.1) and 1.5 (95\% CI, 1.1-2.0).

Ten-year cardiovascular risk profile. According to the FRS analysis, the calculated 10-year cardiovascular risk was $3.0 \%$ (IQR, 0.0-5.0) in the survivors and 3.6\% (IQR, 0.0-6.0) in the controls. When using the SCORE algorithm, these values were $1.6 \%$ (IQR, 0.1-1.7) and 2.0\% (IQR, 0.1-2.7), respectively. 
Table 3. Serum concentration of lipids, glucose and gonadal hormones in GCT survivors according to treatment group and in healthy subjects

Treatment groups

\begin{tabular}{|c|c|c|c|c|c|c|c|c|c|}
\hline $\begin{array}{l}\text { Parameters: median } \\
\text { (min-max) }\end{array}$ & $\begin{array}{c}\text { Healthy } \\
\text { subjects } \\
(\boldsymbol{N}=360)\end{array}$ & $\begin{array}{l}\text { Surgery } \\
(N=58)\end{array}$ & $\begin{array}{l}\text { Carboplatin } \\
(\mathbf{N}=\mathbf{2 1})\end{array}$ & $\begin{array}{l}\text { Combination } \\
\text { CT }(N=176)\end{array}$ & $\begin{array}{l}\text { All survivors } \\
(\mathbf{N}=\mathbf{2 5 5})\end{array}$ & $P$-value ${ }^{\mathrm{a}}$ & $P$-value ${ }^{b}$ & $P$-value ${ }^{c}$ & $\begin{array}{c}\text { Normal } \\
\text { reference range }\end{array}$ \\
\hline
\end{tabular}

Glucose and fat metabolism

\begin{tabular}{|c|c|c|c|c|c|c|c|c|c|}
\hline S. glucose ${ }^{d}$ & $5.1(3.4-7.1)$ & $4.8(3.6-6.5)$ & $5.0(4.1-6.2)$ & $5.1(3.0-9.7)$ & $5.0(3.0-9.7)$ & NS & NS & NS & $\begin{array}{l}3.1-6.4 \\
\mathrm{mmoll}\end{array}$ \\
\hline S. cholesterol ${ }^{\mathbf{e}}$ & $4.90(2.50-8.10)$ & $4.42(2.88-7.11)$ & $5.30(3.75-7.40)$ & $5.20(2.42-9.25)$ & $5.07(2.42-9.25)$ & 0.006 & 0.001 & 0.01 & $\begin{array}{l}3.90-7.30 \\
\mathrm{mmoll}^{-1}\end{array}$ \\
\hline S. HDL-cholesterol ${ }^{\mathbf{e}}$ & $1.34(0.64-2.90)$ & $1.33(0.68-2.70)$ & $1.43(0.94-1.70)$ & $1.36(0.60-4.07)$ & $1.35(0.60-4.07)$ & NS & NS & NS & $\begin{array}{l}0.70-1.50 \\
\mathrm{mmoll}^{-1}\end{array}$ \\
\hline S. LDL-cholesterol ${ }^{\mathbf{e}}$ & $2.88(1.26-5.66)$ & $3.17(1.59-5.28)$ & $3.63(1.77-5.80)$ & $3.46(0.54-7.08)$ & $3.40(0.54-7.08)$ & NS & $<0.001$ & $<0.001$ & $\begin{array}{l}0.70-4.50 \\
\mathrm{mmoll}^{-1}\end{array}$ \\
\hline S. triglyceride ${ }^{\mathbf{e}}$ & $1.17(0.40-4.25)$ & $1.00(0.40-4.31)$ & $1.26(0.67-3.42)$ & $1.27(0.27-7.40)$ & $1.25(0.27-7.40)$ & 0.01 & 0.005 & 0.05 & $\begin{array}{l}0.80-2.30 \\
\mathrm{mmoll}^{-1}\end{array}$ \\
\hline \multicolumn{10}{|c|}{ Gonadal hormones } \\
\hline S. testosterone ${ }^{f}$ & & $16.8(7.6-33.9)$ & $15.8(11.1-25.8)$ & $14.1(6.4-32.1)$ & $14.9(6.4-38.2)$ & 0.04 & & & $8-35\left(\mathrm{nmoll}^{-1}\right)$ \\
\hline S. estradiol & & $69(28-151)$ & 67 (29-106) & $76(10-226)$ & $74(10-226)$ & 0.05 & & & $\begin{array}{c}70-200 \\
\left(\text { pmol I }^{-1}\right)\end{array}$ \\
\hline S. LH & & $5.9(0.1-36.4)$ & $4.7(2.6-25.9)$ & $6.8(0.4-48.1)$ & $6.4(0.1-48.1)$ & NS & & & $2.0-10.0\left(\mathrm{UI}^{-1}\right)$ \\
\hline S. FSH & & $9.7(3.6-46.7)$ & $10.1(3.9-42.8)$ & $14.5(0.2-98.1)$ & $12.4(0.2-98.1)$ & $<0.002$ & & & $2.0-10.0\left(\mathrm{UI}^{-1}\right)$ \\
\hline S. SHBG & & $28(3-75)$ & $28(16-55)$ & $29(2-67)$ & $28(2-75)$ & NS & & & 20-55 (nmoll $\left.{ }^{-1}\right)$ \\
\hline
\end{tabular}

Biochemical parameters

\begin{tabular}{l|c|c|c|c|c|c|c|c|}
$\begin{array}{l}\text { S. lactate } \\
\text { dehydrogenase }\end{array}$ & $319(129-753)$ & $176(130-494)$ & $319(72-531)$ & $316(72-753)$ & NS & $100-248\left(U I^{-1}\right)$ \\
\begin{tabular}{l} 
S. C-reactive protein \\
\hline
\end{tabular} & $<3(<3-18)$ & $<3(<3-6)$ & $<3(<3-30)$ & $<3(<3-30)$ & NS & $<10\left(\mu \mathrm{mol} I^{-1}\right)$ \\
\hline
\end{tabular}

Abbreviations: $\mathrm{CT}=$ chemotherapy; $\mathrm{FSH}=$ follicle-stimulating hormone; $\mathrm{GCT}=$ germ cell tumour; $\mathrm{HDL}=$ high-density lipoprotein; $\mathrm{LDL}=$ low-density lipoprotein; $\mathrm{LH}=$ luteinising hormone; NS = not significant; $\mathrm{S}$. = serum; SHBG = sex hormone-binding globulin.

${ }^{a} P$-value for comparison of gonadal hormones and biochemical parameters between surgery and combination-CT survivors (independent-samples Mann-Whitney used).

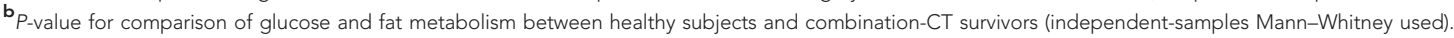

${ }^{c} P$-value for comparison of glucose and fat metabolism between healthy subjects and all survivors (independent-samples Mann-Whitney used).

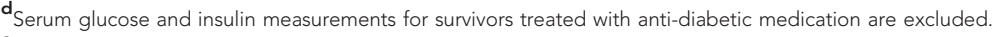

erum cholesterol measurements for survivors treated with cholesterol-lowering medication are excluded.

$\mathbf{f}_{34}$ Survivors; 1 surgery and 31 combination-CT survivors had serum testosterone levels $<10.4 \mu \mathrm{mol} \mathrm{I}^{-1}$

There was no treatment-related difference in age-adjusted 10-year cardiovascular risk in GTC survivors

\section{DISCUSSION}

We observed that the prevalence of the MetS is 2.2- to 2.3-fold higher at a mean duration of 7.8 years after cure in testicular GCT survivors treated with combination CT compared with agematched healthy subjects. In particular, abdominal obesity, hypertension, hypertriglyceridemia, and other dyslipidemias were more frequently observed in CT-treated cancer survivors. Notably, also fasting LDL-cholesterol, which is not included in any MetS classification was consistently higher in all GCT survivors. It is remarkable that in our cohort all GCT survivors, but in particular combination-CT survivors, had higher BMI and were significantly more overweight than controls. In the survivor population, low testosterone concentrations correlated with MetS and the patients treated with combination CT had an average $2.7 \mathrm{nmoll}^{-1}$ lower testosterone than those treated with surgery alone. After adjusting for testosterone, there still was a significant difference in MetS prevalence between the two groups, also after adjusting for age and smoking. In GCT survivors, MetS may be related to a possible preexisting underlying TDS (Skakkebaek et al, 2007) as well as to partial hypogonadism induced by CT, or both. The 10-year cardiovascular risk estimated with either FRS or SCORE was low (3.0\% and $1.6 \%$, respectively) and did not differ between treatment groups or between treatment groups and controls.

Different definitions are used for MetS worldwide, and we show here that depending on the classification that is used, the prevalence of MetS may vary greatly. There was an almost twofold higher absolute MetS prevalence when using IDF (26.9\%) compared with using NCEP-ATPIII (14.6\%). However, the RR for MetS was shown to be independent of the scoring system and showed that GCT survivors had a 1.9- (NCEP-ATPIII) or 1.8-fold higher MetS prevalence compared with controls. The increased prevalence of MetS according to the IDF criteria compared with that of the NCEP-ATPIII has been repeatedly demonstrated in worldwide cohorts (Rathmann et al, 2006). The use of different or adapted scoring systems may also explain why the prevalence of MetS in our cohort varied with those previously reported. Three other cross-sectional studies reported different MetS prevalences in GCT survivors, possibly because of the different methodologies used in the evaluation of the MetS (Table 5). In keeping with our data, Nuver et al (2005) observed a higher MetS prevalence and an increased RR for MetS in a smaller GCT survivor cohort with a similar incidence of MetS in their controls (Table 5). A large multicentre cross-sectional study conducted in five university hospitals in Norway (Haugnes et al, 2007) reported an unusually 


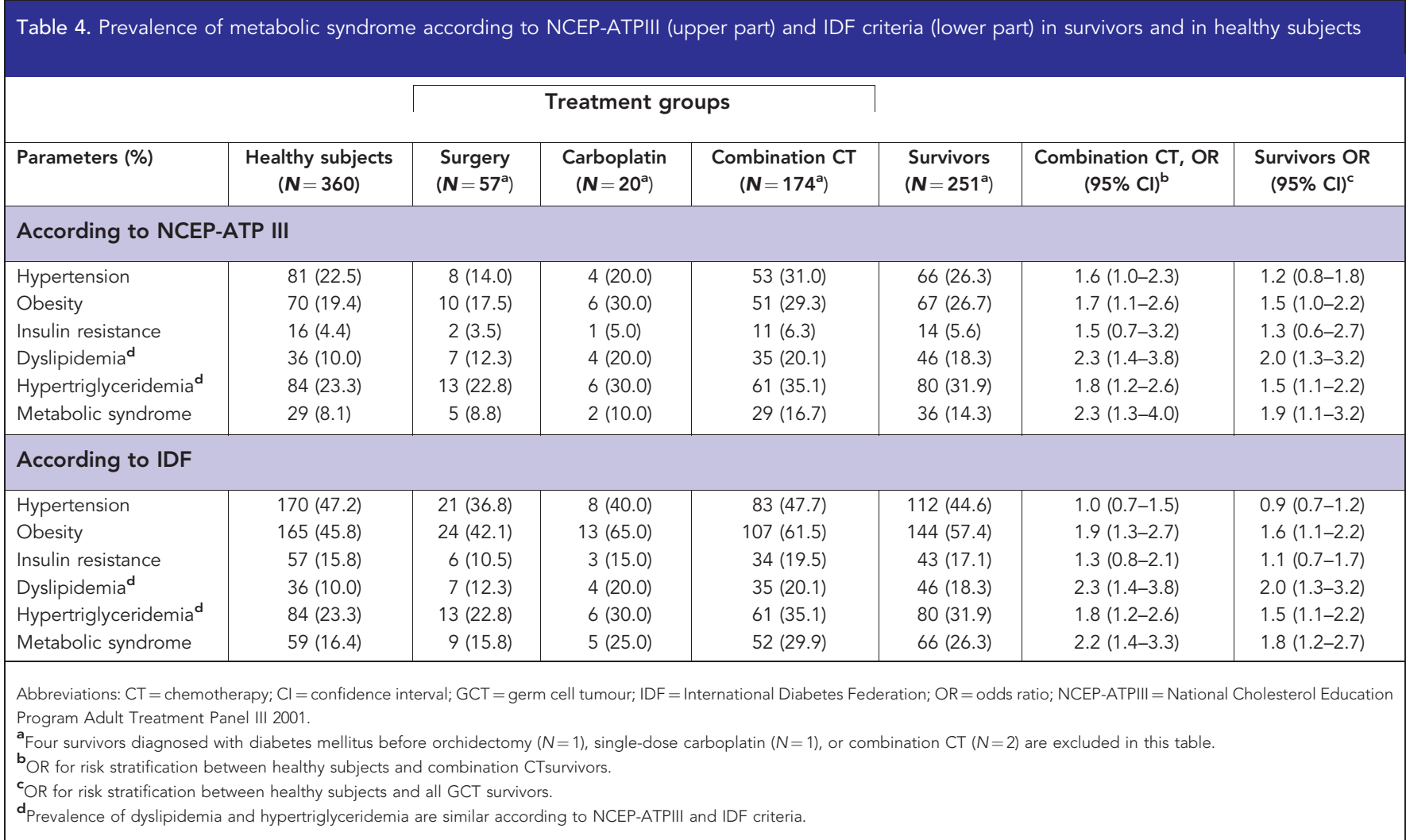

high MetS prevalence of $52 \%$ in healthy subjects, and $45 \%$ and $33 \%$, respectively, in GCT survivors treated with CT or orchidectomy alone. Discrepancies may be explained by nonadherence to the 2002 NCEP-ATPIII classification, the use of nonfasting blood samples, using (at least two) modified criteria to assess the MetS and of only serum total cholesterol. In another report from a single institution (Wethal et al, 2007), which participated in the multicentre study (Haugnes et al, 2007), the authors also did not adhere to above mentioned classification methodology, which may have led to an overestimation of MetS.

As in other studies the high prevalence of MetS does not necessarily translate into increased cardiovascular risk. In keeping with the $2.2 \%$ cumulative incidence reported by Haugnes et al (2008) in their patients, our GCT survivors have a low 10-year cardiovascular risk of $3.0 \%$ as estimated by FRS. This risk estimate is similar to that observed in the general population by van den Belt-Dusebout et al (2006) and to the 3.0\% cardiovascular risk reported for another Dutch cohort of 408 healthy males of the same age (de Visser et al, 2003). Although FRS calculations for individuals under the age of 40 years are less specific, a main shortcoming of MetS prediction for cardiovascular events is that it does not take into account major risk factors for CVD, such as age, exercise, and smoking status. The association between the severity of risk factors and CVD risk is also not taken in consideration in the MetS criteria.

Our cross-sectional single-centre study has some limitations, including the relatively short follow-up time after cure, related to the past policy of discharging GCT patients 5 years after establishment of cure. Moreover, the subgroup of patients who received only one single administration of carboplatin is relatively small, as single-dose adjuvant carboplatin has only recently been introduced as an alternative treatment in patients with stage-I seminoma (Oliver et al, 2005; Krege et al, 2008). Although few patients received adjuvant carboplatin treatment, the data suggest that the cumulative dose of cisplatin added to that of cytotoxic drugs of the standard combination drug regimens is a decisive determinant to develop MetS. Although more of our GCT patients were smokers than controls, adjustment for smoking differences did not alter the significantly increased MetS prevalence in combination-CT patients. This was also the case when all survivors were compared with healthy subjects. Finally, it may be argued that there was a substantial variability in the time that had elapsed between the diagnosis and initial treatment and the time of assessment of the survivors. However, we investigated whether there was a time dependency between the time of assessment and the prevalence of MetS, and whether there was only a weak association between these variables. This suggests that the effects of combination CT are likely to be acute and maintained over time. Thirty to fifty per cent of GCT patients treated with CT are infertile and most of the GCT survivors have long-term partial or complete hypogonadism (Berger et al, 1996). As a proportion of GCT patients already have TDS, it is unknown whether the infertility results from this condition, the CT, or from both (Williams et al, 2009). Whatever the explanation is, low testosterone and SHBG levels are considered risk factors for MetS in otherwise healthy men (Muller et al, 2005; Kupelian et al, 2006; Miner and Sadovsky, 2007). We indeed found an association between low serum concentrations of testosterone and MetS in all patients and, in particular, CT patients, but there was no association between SHBG, LH, or FSH levels and MetS. We argue that because hypogonadism is associated with increased cardiovascular risk GCT survivors should be treated with testosterone supplementation. Although testosterone supplementation has not (yet) been shown to prevent CVD, clinical trials with testosterone supplementation have resulted in a significant reduction of cholesterol levels (Fernandez-Balsells et al, 2010; Monroe and Dobs, 2013). Apart from these favourable effects on lipid metabolism, testosterone supplementation also results in increased BMD, muscle mass, and fat-free body mass (Snyder et al, 2000; Aversa et al, 2010). In particular, use of daily transdermal testosterone gel may be attractive, as this is reported to be without side effects. As the risk to develop prostate cancer after long-term use of 
Table 5. Metabolic syndrome prevalence and odds ratio's in four cross-sectional studies

\begin{tabular}{|c|c|c|c|c|c|c|}
\hline Parameters & $\begin{array}{l}\text { Nuver et al } \\
(2005)\end{array}$ & $\begin{array}{l}\text { Haugnes et al } \\
\text { (2007) }\end{array}$ & & $\begin{array}{c}\text { Wethal et al } \\
\text { (2007) }\end{array}$ & this study & \\
\hline $\begin{array}{l}\text { Number of survivors } \\
\text { Mean age (years) (range) } \\
\text { Mean follow-up time (years) } \\
\text { (range) } \\
\text { Healthy subjects }(N) \\
\text { Metabolic syndrome } \\
\text { definition }\end{array}$ & $\begin{array}{c}130 \\
38.5(20-65) \\
7.5(3-13) \\
\\
47 \\
\text { NCEP-ATP III }\end{array}$ & $\begin{array}{c}1135 \\
42.5(23-60) \\
11.2(5-22) \\
1150 \\
\text { Modified NCEP-ATP III } \\
\geqslant 2 \text { criteria }^{\text {a }}\end{array}$ & $\begin{array}{c}\text { Modified NCEP-ATP III } \\
\quad \geqslant 3 \text { criteria }^{\text {a }}\end{array}$ & $\begin{array}{c}589 \\
42(23-60) \\
11(7.7-14.5) \\
\\
\quad 8835 \\
\text { Modified criteria } \\
\geqslant 3 \text { criteria }^{a}\end{array}$ & $\begin{array}{c}251 \\
39.6(18-70) \\
7.8(0.1-30.0) \\
360 \\
\text { NCEP-ATP III }\end{array}$ & IDF \\
\hline \multicolumn{7}{|c|}{ Metabolic syndrome prevalence (\%) } \\
\hline $\begin{array}{l}\text { All GCT survivors } \\
\text { Combination CT } \\
\text { Single-dose carboplatin } \\
\text { Radiotherapy } \\
\text { Surgery only } \\
\text { Healthy subjects }\end{array}$ & $\begin{array}{c}38(29.2) \\
22(25.6) \\
\sim \\
\sim \\
16(34.0) \\
4(8.5)\end{array}$ & $\begin{array}{r}447(39.4) \\
191(41.2) \\
\sim \\
184(42.0) \\
72(33.0) \\
584(51.5)\end{array}$ & $\begin{array}{c}92(8.1) \\
40(8.6) \\
\sim \\
37(8.3) \\
15(6.7) \\
170(14.8)\end{array}$ & $\begin{array}{c}82(13.9) \\
38(17.4) \\
\sim \\
35(15.2) \\
9(6.4) \\
\text { Not mentioned }\end{array}$ & $\begin{array}{c}36(14.3) \\
29(16.7) \\
2(10.0) \\
\sim \\
5(8.8) \\
29(8.1)\end{array}$ & $\begin{array}{c}66(26.3) \\
52(29.9) \\
5(25.0) \\
\sim \\
9(15.8) \\
59(16.4)\end{array}$ \\
\hline \multicolumn{7}{|l|}{ OR $(95 \% \mathrm{Cl})$ adjustments $^{\mathrm{b}}$} \\
\hline $\begin{array}{l}\text { GCT survivors vs healthy } \\
\text { subjects } \\
\text { Combination CT vs healthy } \\
\text { subjects } \\
\text { Combination chemotherapy } \\
\text { vs surgery only }\end{array}$ & $\begin{array}{l}4.4(1.5-13.2) \\
3.7(1.2-11.5) \\
0.6(0.3-1.3)\end{array}$ & $\begin{array}{l}0.6(0.5-0.7) \\
0.7(0.5-0.8) \\
1.5(1.1-2.1)\end{array}$ & $\begin{array}{l}0.5(0.4-0.7) \\
0.5(0.4-0.8) \\
1.3(0.7-2.4)\end{array}$ & $\begin{array}{c}\sim \\
3.7(1.5-9.1) \\
3.1(1.4-6.6)\end{array}$ & $\begin{array}{l}1.9(1.1-3.2) \\
2.3(1.3-4.0) \\
2.1(0.8-5.7)\end{array}$ & $\begin{array}{l}1.8(1.2-2.7) \\
2.2(1.4-3.3) \\
2.3(1.0-5.0)\end{array}$ \\
\hline
\end{tabular}

transdermal androgens is currently unknown, it may be prudent to consider monitoring of PSA when initiating treatment (Lakshman and Basaria, 2009).

Our data confirm that according to the NCEP-ATPIII and IDF criteria, the subgroup of hypogonadal GCT survivors who received combination CT is the main group at increased risk for developing a MetS compared with the general population. We observed no clear increase in the calculated 10-year CVD risk in long-term GCT survivors, although the follow-up period was perhaps too short. Long-term CT-related cardiovascular toxicity may result from acute direct endothelial damage or from indirect long-term CT-induced hormonal and metabolic changes, including liver and gut damage, thereby affecting lipid uptake, transport, and metabolism over a period of many years.

In conclusion, our findings suggest an increased prevalence of MetS in GTC survivors who received CT. Of these CT patients, we further identify patients with low androgen levels as a subgroup that is particularly at risk of developing MetS. On the basis of this important clinical finding we advocate that guidelines to monitor blood pressure, lipid- and glucose metabolism, and assessment of gonadal hormone status should be introduced in international urology/oncology guidelines rather than monitoring potential complications of treatment. This is particularly important, as the current standard of follow-up is focused on the detection of tumour recurrence. In our opinion, this would allow for evidencebased counselling of GCT survivors to adhere to a lifestyle that favourably affects the modifiable risk factors for MetS and cardiovascular risk, such as regular exercise, low-carbohydrate diet, and smoking cessation. We would be in favour of correcting androgen deficiency more liberally in this group of relatively young male cancer survivors. Obviously, the beneficial effect of this intervention on prevention or reversal of the MetS remains to be established, but longer-lasting intervention studies should be able to establish whether this approach of lifetime monitoring, lifestyle intervention, and correction of hypogonadism by wider use of testosterone supplementation at some stage during the natural course of GCT may prevent or revert the development of MetS and associated risk of CVD in long-term survivors of GCT.

\section{CONFLICT OF INTEREST}

The authors declare no conflict of interest.

\section{REFERENCES}

Alberti KG, Zimmet P, Shaw J (2006) Metabolic syndrome-a new worldwide definition. A Consensus Statement from the International Diabetes Federation. Diabet Med 23: 469-480.

Aversa A, Bruzziches R, Francomano D, Spera G, Lenzi A (2010) Efficacy and safety of two different testosterone undecanoate formulations in hypogonadal men with metabolic syndrome. J Endocrinol Invest 33: 776-783.

Balkau B, Charles MA (1999) Comment on the provisional report from the WHO consultation. European Group for the Study of Insulin Resistance (EGIR). Diabet Med 16: 442-443.

Berger CC, Bokemeyer C, Schuppert F, Schmoll HJ (1996) Endocrinological late effects after chemotherapy for testicular cancer. Br J Cancer 73: 1108-1114.

Carver JR, Shapiro CL, Ng A, Jacobs L, Schwartz C, Virgo KS, Hagerty KL, Somerfield MR, Vaughn DJ (2007) American Society of Clinical Oncology clinical evidence review on the ongoing care of adult cancer survivors: cardiac and pulmonary late effects. J Clin Oncol 25: 3991-4008.

Conroy RM, Pyorala K, Fitzgerald AP, Sans S, Menotti A, De BG, De BD, Ducimetiere P, Jousilahti P, Keil U, Njolstad I, Oganov RG, Thomsen T, Tunstall-Pedoe H, Tverdal A, Wedel H, Whincup P, Wilhelmsen L, 
Graham IM (2003) Estimation of ten-year risk of fatal cardiovascular disease in Europe: the SCORE project. Eur Heart J 24: 987-1003.

de Forni M, Armand JP (1994) Cardiotoxicity of chemotherapy. Curr Opin Oncol 6: 340-344.

de Visser CL, Bilo HJ, Thomsen TF, Groenier KH, Meyboom-de JB (2003) Prediction of coronary heart disease: a comparison between the Copenhagen risk score and the Framingham risk score applied to a Dutch population. J Intern Med 253: 553-562.

Einhorn EH (1997) Testicular cancer: an oncological success story. Clin Cancer Res 3: 2630-2632.

Fernandez-Balsells MM, Murad MH, Lane M, Lampropulos JF, Albuquerque F, Mullan RJ, Agrwal N, Elamin MB, Gallegos-Orozco JF, Wang AT, Erwin PJ, Bhasin S, Montori VM (2010) Clinical review 1: adverse effects of testosterone therapy in adult men: a systematic review and meta-analysis. J Clin Endocrinol Metab 95: 2560-2575.

Galassi A, Reynolds K, He J (2006) Metabolic syndrome and risk of cardiovascular disease: a meta-analysis. Am J Med 119: 812-819.

Gami AS, Witt BJ, Howard DE, Erwin PJ, Gami LA, Somers VK, Montori VM (2007) Metabolic syndrome and risk of incident cardiovascular events and death: a systematic review and meta-analysis of longitudinal studies. J Am Coll Cardiol 49: 403-414.

Haugnes HS, Aass N, Fossa SD, Dahl O, Klepp O, Wist EA, Svartberg J, Wilsgaard T, Bremnes RM (2007) Components of the metabolic syndrome in long-term survivors of testicular cancer. Ann Oncol 18: 241-248.

Haugnes HS, Aass N, Fossa SD, Dahl O, Klepp O, Wist EA, Wilsgaard T, Bremnes RM (2008) Predicted cardiovascular mortality and reported cardiovascular morbidity in testicular cancer survivors. J Cancer Surviv 2: 128-137.

Haugnes HS, Wethal T, Aass N, Dahl O, Klepp O, Langberg CW, Wilsgaard T, Bremnes RM, Fossa SD (2010) Cardiovascular risk factors and morbidity in long-term survivors of testicular cancer: a 20 -year follow-up study. J Clin Oncol 28: 4649-4657.

Hu G, Qiao Q, Tuomilehto J, Balkau B, Borch-Johnsen K, Pyorala K (2004) Prevalence of the metabolic syndrome and its relation to all-cause and cardiovascular mortality in nondiabetic European men and women. Arch Intern Med 164: 1066-1076.

Huddart RA, Norman A, Shahidi M, Horwich A, Coward D, Nicholls J, Dearnaley DP (2003) Cardiovascular disease as a long-term complication of treatment for testicular cancer. J Clin Oncol 21: 1513-1523.

Ingelsson E, Arnlov J, Lind L, Sundstrom J (2006) Metabolic syndrome and risk for heart failure in middle-aged men. Heart 92: 1409-1413.

Ivell R, Nand-Ivell R (2009) Biology of insulin-like factor 3 in human reproduction. Hum Reprod Update 15: 463-476.

Krege S, Beyer J, Souchon R, Albers P, Albrecht W, Algaba F, Bamberg M, Bodrogi I, Bokemeyer C, Cavallin-Stahl E, Classen J, Clemm C, Cohn-Cedermark G, Culine S, Daugaard G, De Mulder PH, De SM, de WM, de WR, Derigs HG, Dieckmann KP, Dieing A, Droz JP, Fenner M, Fizazi K, Flechon A, Fossa SD, del X M, Gauler T, Geczi L, Gerl A, Germa-Lluch JR, Gillessen S, Hartmann JT, Hartmann M, Heidenreich A, Hoeltl W, Horwich A, Huddart R, Jewett M, Joffe J, Jones WG, Kisbenedek L, Klepp O, Kliesch S, Koehrmann KU, Kollmannsberger C, Kuczyk M, Laguna P, Galvis OL, Loy V, Mason MD, Mead GM, Mueller R, Nichols C, Nicolai N, Oliver T, Ondrus D, Oosterhof GO, Ares LP, Pizzocaro G, Pont J, Pottek T, Powles T, Rick O, Rosti G, Salvioni R, Scheiderbauer J, Schmelz HU, Schmidberger H, Schmoll HJ, Schrader M, Sedlmayer F, Skakkebaek NE, Sohaib A, Tjulandin S, Warde P, Weinknecht S, Weissbach L, Wittekind C, Winter E, Wood L, von der MH (2008) European consensus conference on diagnosis and treatment of germ cell cancer: a report of the second meeting of the European Germ Cell Cancer Consensus group (EGCCCG): part I. Eur Urol 53: 478-496.

Kupelian V, Page ST, Araujo AB, Travison TG, Bremner WJ, McKinlay JB (2006) Low sex hormone-binding globulin, total testosterone, and symptomatic androgen deficiency are associated with development of the metabolic syndrome in nonobese men. J Clin Endocrinol Metab 91: 843-850.

Lackner JE, Mark I, Schatzl G, Marberger M, Kratzik C (2007) Hypogonadism and androgen deficiency symptoms in testicular cancer survivors. Urology 69: 754-758.
Lakshman KM, Basaria S (2009) Safety and efficacy of testosterone gel in the treatment of male hypogonadism. Clin Interv Aging 4: 397-412.

Miner MM, Sadovsky R (2007) Evolving issues in male hypogonadism: evaluation, management, and related comorbidities. Cleve Clin J Med 74(Suppl 3): S38-S46.

Monroe AK, Dobs AS (2013) The effect of androgens on lipids. Curr Opin Endocrinol Diabetes Obes 20: 132-139.

Muller M, Grobbee DE, den Tonkelaar I, Lamberts SW, van der Schouw YT (2005) Endogenous sex hormones and metabolic syndrome in aging men. J Clin Endocrinol Metab 90: 2618-2623.

National Cholesterol Education Program (NCEP) Expert Panel on Detection, Evaluation, and Treatment of High Blood Cholesterol in Adults (Adult Treatment Panel III) (2002) Third Report of the National Cholesterol Education Program (NCEP) Expert Panel on Detection, Evaluation, and Treatment of High Blood Cholesterol in Adults (Adult Treatment Panel III) final report. Circulation 106: 3143-3421.

Nord C, Fossa SD, Egeland T (2003) Excessive annual BMI increase after chemotherapy among young survivors of testicular cancer. Br J Cancer 88: $36-41$.

Nuver J, Smit AJ, Wolffenbuttel BH, Sluiter WJ, Hoekstra HJ, Sleijfer DT, Gietema JA (2005) The metabolic syndrome and disturbances in hormone levels in long-term survivors of disseminated testicular cancer. J Clin Oncol 23: $3718-3725$.

Oliver RT, Mason MD, Mead GM, von der MH, Rustin GJ, Joffe JK, de WR, Aass N, Graham JD, Coleman R, Kirk SJ, Stenning SP (2005) Radiotherapy versus single-dose carboplatin in adjuvant treatment of stage I seminoma: a randomised trial. Lancet 366: 293-300.

Rathmann W, Haastert B, Icks A, Giani G, Holle R, Koenig W, Lowel H, Meisinger C (2006) Prevalence of the metabolic syndrome in the elderly population according to IDF, WHO, and NCEP definitions and associations with C-reactive protein: the KORA Survey 2000. Diabetes Care 29: 461.

Skakkebaek NE, Rajpert-De ME, Jorgensen N, Main KM, Leffers H, Andersson AM, Juul A, Jensen TK, Toppari J (2007) Testicular cancer trends as 'whistle blowers' of testicular developmental problems in populations. Int J Androl 30: 198-204.

Snyder PJ, Peachey H, Berlin JA, Hannoush P, Haddad G, Dlewati A, Santanna J, Loh L, Lenrow DA, Holmes JH, Kapoor SC, Atkinson LE, Strom BL (2000) Effects of testosterone replacement in hypogonadal men. J Clin Endocrinol Metab 85: 2670-2677.

van den Belt-Dusebout AW, Nuver J, de WR, Gietema JA, ten Bokkel Huinink WW, Rodrigus PT, Schimmel EC, Aleman BM, van Leeuwen FE (2006) Long-term risk of cardiovascular disease in 5-year survivors of testicular cancer. J Clin Oncol 24: 467-475.

Wethal T, Kjekshus J, Roislien J, Ueland T, Andreassen AK, Wergeland R, Aukrust P, Fossa SD (2007) Treatment-related differences in cardiovascular risk factors in long-term survivors of testicular cancer. J Cancer Surviv 1: 8-16.

Williams DH, Karpman E, Sander JC, Spiess PE, Pisters LL, Lipshultz LI (2009) Pretreatment semen parameters in men with cancer. J Urol 181: 736-740.

Wilson PW, Castelli WP, Kannel WB (1987) Coronary risk prediction in adults (the Framingham Heart Study). Am J Cardiol 59: 91G-94G.

World Health Organization (1999) Definition, diagnosis and classification of diabetes mellitus and its complications: report of a WHO Consultation. World Health Organization Part 1: diagnosis and classification of diabetes mellitus. Geneva, Swit-zerland: World Health Organization. Available at: http://apps.who.int/iris/bitstream/10665/66040/1/WHO_NCD_NCS_99.2.pdf.

Yeh ET, Tong AT, Lenihan DJ, Yusuf SW, Swafford J, Champion C, Durand JB, Gibbs H, Zafarmand AA, Ewer MS (2004) Cardiovascular complications of cancer therapy: diagnosis, pathogenesis, and management. Circulation 109: 3122-3131.

This work is published under the standard license to publish agreement. After 12 months the work will become freely available and the license terms will switch to a Creative Commons AttributionNonCommercial-Share Alike 3.0 Unported License. 